\title{
Applications Research of Artistic Style of Chinese Landscape Painting in Modern Landscape Design
}

\author{
Jing Li \\ Heilongjiang University of Technology, Jixi, 158100, China \\ Email: ljjx@126.com
}

Keywords: Chinese Landscape painting; Mountains-and-waters painting; Landscape design

\begin{abstract}
With the rapid development of urbanization in China, people's requirements for the reasonable and beautiful landscape design are increasingly growing in recent years. Landscape painting is an art of unparalleled charm which has been inherited in ancient China and its artistic expression can be applied in modern landscape design. This paper analyzes the inner relationship between the artistic style of Chinese landscape painting and the modern landscape design and gives the expression models of the landscape painting in the modern landscape design to provide some references for the relative researchers.
\end{abstract}

\section{Introduction}

The prosperity of the economy and the improvement of environmental awareness make China's landscape industry enter a transformation period [1]. The combination of modern landscape design and art creates a more artistic design. The content and form of landscape are also changing dramatically. The overall image of the city is designed to the city node, such as city square, city park, Riverside hydrophilic space, block landscape, street green space, residential environment design and so on; small to sculpture sketches, planting configuration, pond flower pool, paving railing, table stool garbage box, almost cover all outdoor plastic arts. However, in the period of economic and cultural transformation, the practice of urban landscape falls into the mire of formalism, and there are some common problems and misunderstandings. China's small and medium-sized cities basically have the same urban appearance. The main body of the city is the large and small building and the geometric layout of the road. Blindly imitate others, destroy the environment, destroy their homes everywhere. Especially in recent years, the rapid development of economy makes the traditional landscape features in city, in jeopardy. Some landscape designs are too dull and lack of artistic value; or too much emphasis on art form to keep people away from nature; and some pure functionalist works have good sociality, but they are isolated from culture and nature, and not with human interest. People live in the city of steel, concrete and glass, the ecological environment of the city has been greatly destroyed, at the same time, it is also a kind of devastation to people's heart, and a variety of modern diseases are constantly produced. How to integrate landscape painting with modern urban landscape design and reproduce the survival state of human in landscape painting is worthy of our consideration [2].

\section{Relationship between Artistic Style of Chinese Landscape Painting and Modern Landscape Design}

\subsection{Artistic Style of Chinese Landscape Painting}

Every nation and every country have its own leading philosophy. To a large extent, art is influenced by its geographical environment and background. Chinese landscape painting is a school in the history of world art. Landscape painting is drawn by the painter after careful observation of the scene, using the unique way of thinking and special painting material. Chinese landscape painting has 
the unique beauty of art and has the characteristics that can surpass the time and space. It comes from the wide space of artistic creation that the Confucianism, Buddhism and Taoism have interacted with each other. The reason why Chinese landscape painting can be unique in the world art forest is that Chinese landscape painting artists have a more comprehensive grasp of natural scenery. They cannot be bound by time and space when they are created. In addition, Chinese people have unique aesthetic consciousness and intellectual wisdom, with unique spatial expression and painting. The special understanding of the surface space creates the artistic treasure with deep cultural details. The emergence of artistic conception needs to experience emotion, scenery and scenery, and finally achieve the process of feeling and blending. The creation of the artistic conception of landscape painting starts from the beginning of the creation, which is the basis of the creation of the artistic conception of the landscape painting, including the determination of the theme, the selection of the material, the form of the scene and the expression of the art. Performance. The theme of the landscape painting is mainly to depict the scene of nature. In the process of creation, the author combines the mountains and rocks, water and trees in nature through the ingenious composition of the picture to deal with the virtual reality of the picture [3].

\subsection{Modern Landscape Design}

Landscape design is an active arrangement of human environment, through which people coordinate the whole ecosystem, including culture and nature. The existence of landscape design art is intended to help people get a better life, make people, society, city and nature live in harmony. It pays attention to the humanistic value of the harmonious relationship between people and the environment. The most popular interpretation of modern landscape design art is to beautify the environment. This beautification process needs to be realized under certain economic conditions. It must satisfy a considerable social function and conform to the law of natural ecology. At the same time, it is also subordinate to the category of art. In today's China, the construction of modern landscape is raging. However, there are many problems in this new subject area, such as the blending and collision of the East and the West multiculturalism, the transformation and conflict between the different attributes of the traditional and the modern, and if it is not handled properly, it will inevitably lead to the false prosperity of the modern landscape design and art industry and the landscape environment. Urban landscape is both an experience and an environment. They can sustain culture and civilization and can also sustain biological and physical environment. Landscape is the inevitable product of social and economic development. It is also an important public open space in peaceful and comfortable life. Its role is diverse. Apart from the well-known landscaping function, landscape in the aspect of environmental protection can maintain regional ecosystem and guide regional development form macroscopically. Microscopically, it can regulate micro air and restrain urban public nuisance. As for landscape, it can regulate flood, prevent collapse, curb fire and provide shelter and shelter [4].

\subsection{Inherent Relationship between Artistic Style of Chinese Landscape Painting and Modern Landscape Design}

Landscape is a unique way for Chinese people to connect nature and culture. From the elaboration of Chinese people's landscapes in the previous landscape paintings, we can see that Chinese people's feelings for mountains and waters are not bad. People with cultural development to a certain extent have their own garden landscapes. The traditional Chinese garden design concept is deeply influenced by the Chinese people's common landscape plot. It is a kind of human nature to take the natural environment as the object of aesthetic and the landscape of the landscape created by the art. As the basis of Chinese landscape art, Chinese classical gardens, landscapes are the main signs. There are almost no gardens, no hills, no gardens and no water. Appreciating mountains and waters can make people get rid of the trouble of daily trifles, and get a moment's peace in mind, so that spirit can be sublimated, purified and enriched. It shows that in the cosmological schema understood by the Chinese people in the concept of yin and Yang, nature includes two worlds, both external and internal, and the beauty of nature exists in the harmonious balance between the subjective world and the 
objective existence. Therefore, the way for Chinese people to explore the beauty of nature is to find their inevitability through careful observation and deep understanding and association. Besides, Taoism also implies a sense of transcending rational thinking, and emphasizes the importance of real experience. Landscape design itself is an effective way of coordination between human and environment. People come out of nature and will return to his familiar natural environment, worship nature and return to nature as the pursuit of modern urban development. This is also the embodiment of the natural view contained in Chinese landscape painting in the new era. The artistic conception pursued in landscape design coincides with the landscape painting. The value of traditional landscape paintings is rediscovered by modern landscape architects.

\section{Performance of Artistic Style of Chinese Landscape Painting in Modern Landscape Design}

\subsection{Performance of Artistic Style of Mountains in Modern Landscape Design}

The ancient Chinese landscape painter is mostly the literati class, among which there is no lack of knowledge and knowledge of the way of the wind and water, so the realm of landscape painting, although it is processed by art, comes from nature and is higher than nature, but there is still a breath of life. The natural landscape in landscape painting shows us many kinds of artistic conception, but the themes are mountains, water and trees. China is a country with a large range of mountains. In modern cities with mountains, we can directly draw on the combination of mountains in landscape painting and combine the characteristics of urban architecture to pursue a multilevel landscape. In the cities without mountains, we can understand the high buildings in the city as mountains in the landscape painting and carry out the urban landscape construction according to the layout of the mountains in the landscape painting. The layout law of the landscape painting in the range of mountain range have a certain program. In view of the landscape painting, the main mountain range is flatter, the main peak is sloping down slowly down, and the residential area is in front of the main peak, and the main peak can block the coming wind from the valley behind. The main mountains are divided into two branches, surrounded by residential areas, which can block the strong winds around the left and right sides, maintain the temperature and humidity of residential areas, and keep ventilation and ventilation free. In the urban landscape design, we can draw on this layout mode, carry out the main and secondary distribution of the high building in the city, to keep the circulation of the air and the rhythm of the building. Mountains and rivers are also concerned with the ups and downs, trends and situations of mountains. From the point of view of painting, it is from the consideration of the composition, because most of the mountains occupy the frame, so the change of the mountain range is directly related to the rhyme of the picture composition. Chinese painting pays attention to the charm and vividness. Therefore, judging the quality of a landscape painting depends largely on the arrangement of mountains in the picture.

\subsection{Performance of Artistic Style of Water in Modern Landscape Design}

The tree, mountain and stone in the landscape painting need to describe the material and mechanism of the object by the method of pen, ink and water. And in the process of landscape painting creation, through the ingenious combination of ink and water, we can create a flowing beauty, fresh and elegant mechanism. Strong perspective, but also emphasize the shaping of volume. In a landscape painting, the mountain and the tree are all volume. To describe their volume, the water and the ink need to be fully harmonizing and flexibly used. By harmonizing the ink in the light, dry and wet and dry and so on, the volume sense of the works arises spontaneously. Water is a flowing, continuous and tenacious feeling, with clear guidance and directivity, and has an indispensable role in the coordination of space organization and landscape change. In a word, water has the unparalleled aesthetic nature of other garden elements. In garden design, by arranging the scenery and fully reflecting the characteristics of the water landscape, we can play the charm of the garden, and the garden is more appealing. Water is one of the elements of landscaping. It is also an important part of landscaping design, and it is a most attractive design constituent element. The construction of 
waterscape cannot be separated from mountains, stones and all kinds of plants. It is not separated from water in the landscape painting. The types of water are mainly divided into dynamic water and static water. The static water scenery is relatively calm and heavy, its form has lakes, ponds and so on. The focus is on the art treatment. The dynamic water scenery is more lively and lively can buffer and soften the reinforced concrete buildings in the city, increase the vitality of the urban environment, enhance the beauty of the visual art, and its form has fountain, reiterative water and so on. In the landscape painting, whether it is the residence of the Royal aristocracy, or the living and production area of the common people, there are rivers and many places in the tortuous and tortuous areas of the river. In view of this, we can draw on this feature in the urban landscape design, the rational layout of water in modern city design, and the flow of water, such landscape design can not only beautify the city design but also clean the air. In modern urban landscape, because of the lack of natural physical scenery in most cities, most of the metropolis in the tall buildings are the straight streets and the endless stream of people. We should think of straight roads and crowds as dynamic rivers, see the squares as static pools, and arrange them according to the way of water distribution in landscape paintings.

\subsection{Performance of Artistic Style of Trees in Modern Landscape Design}

The collocation of the plants in the landscape painting is very particular. Artists use different plant characters and spiritual symbols to express different mood. Like plum blossom and bamboo, express the spirit of the painter's tenacity and indifference. The collocation of bamboo and orchid embodies the painter's style of gentleman and the quality of his personal personality. Plants are important graphic languages to express the artistic conception in landscape paintings. Painters often arrange their plants according to their different aesthetic functions and morphological characteristics. In the landscape painting, the trees are more embellished with the mountains, and they add and arrange the categories of the trees around the main body, which enriches the content of the picture and expands the spatial level of the picture. By analyzing the rule of tree layout in landscape painting, we can apply the rule to modern urban landscape design. In the design of urban landscape, the arrangement of trees' combination and dispersion should be arranged to enrich the level of space. According to the characteristics of different plants and the colors presented in different seasons, a reasonable collocation is made to make the color varied on the level, to ensure the long-term bird's fragrance around the residence and make the environment full of vitality. Trees can also effectively divide and coordinate the role of landscape space, such as park greening, residential landscapes, etc. In addition, the planting of trees can also play the role of fresh air, climate adjustment, solid soil, adsorption of poisonous gas and smoke and dust. It can be said that there is no harm to the city landscape construction. We apply the vegetation in the landscape painting to the landscape design of the residential area to build the living area environment.

\section{Conclusion}

The traditional landscape painting is a kind of art which has the unparalleled charm which has been circulated in ancient China. Its spatial concept and its expression in the space artistic conception can be applied to the modern landscape design. The combination of the spatial concept of Chinese traditional landscape painting and the modern landscape design can create China. Own landscape design with national characteristics and national characteristics.

\section{References}

[1] Xu Sijing, Chen Fan. A Study of Modern Landscape Design Based on Functions of Classical Landscape Paintings [J]. Journal of Nanjing Forestry University (Humanities and Social Sciences Edition), 2015(1): 98-105.

[2] Wei Yunfei. Achievements and Regrets of Cao Zhibai’s Mountains-and-Waters Painting [J]. Journal of Tianjin Academy of Fine Arts, 2015(5): 95-97. 
[3] Wang Yichuan, Ma Lianjing, Liu Yang. Application of Chinese Landscape Painting Ambience in Modern Residential Landscape [J]. Journal of Landscape Research, 2012, 4(10): 14-17.

[4] Bai Yang. Artistic Idea-Realm of Integration between Chinese and Western Style in Contemporary Chinese Water-Mountain Painting [J]. Hundred Schools In Arts, 2017(3): 221-222. 